\title{
Fabrication of Nanostructured Cadmium Selenide Thin Films for Optoelectronics Applications
}

\author{
Shahnwaz Hussain ${ }^{1}$, Mazhar lqbal ${ }^{2}$, Ayaz Arif Khan ${ }^{2}$, Muhammad Nasir Khan ${ }^{3}$, \\ Ghazanfar Mehboob ${ }^{1}$, Sohaib Ajmal ${ }^{2}$, J. M. Ashfaq ${ }^{4}$, Gohar Mehboob ${ }^{5}$, \\ M. Shafiq Ahmed ${ }^{4 *}$, Said Nasir Khisro ${ }^{4}$, Chang-Jiu Li ${ }^{1}$, Raphael Chikwenze ${ }^{6}$ and \\ Sabastine Ezugwu ${ }^{7}$
}

'State Key Laboratory for Mechanical Behavior of Materials, School of Materials Science and Engineering, Xi'an Jiaotong University, Xi'an, China, ${ }^{2}$ Department of Physics, University of Azad Jammu and Kashmir, Muzaffarabad, Pakistan, ${ }^{3}$ Central Diagnostic Laboratory (CDL), Physics Division, Pakistan Institute of Nuclear Science and Technology (PINSTECH), Islamabad, Pakistan, ${ }^{4}$ Department of Physics, University of Kotli Azad Jammu and Kashmir, Kotli, Pakistan, ${ }^{5}$ School of Materials Science and Engineering, South China University of Technology, Guangzhou, China, ${ }^{6}$ Department of Physics, Faculty of Sciences, Alex Ekwueme Federal University Ndufu-Alike Ikwo, Abakaliki, Nigeria, ${ }^{7}$ Department of Physics \& Astronomy, University of Western Ontario, London, ON, Canada

OPEN ACCESS

Edited by:

Ghulam Ali,

National University of Sciences and Technology (NUST), Pakistan

Reviewed by:

Shoyeb Shaikh,

King Saud University, Saudi Arabia Rajaram Mane

Swami Ramanand Teerth Marathwada

University, India

*Correspondence:

M. Shafiq Ahmed

mshafiq@uokajk.edu.pk;

mahmed88@alumni.uwo.ca

Specialty section

This article was submitted to Electrochemistry,

a section of the journal

Frontiers in Chemistry

Received: 31 January 2021

Accepted: 08 March 2021

Published: 07 April 2021

Citation:

Hussain S, lqbal M, Khan AA,

Khan MN, Mehboob G, Ajmal S, Ashfaq JM, Mehboob G, Ahmed MS, Khisro SN, Li C-J, Chikwenze R and

Ezugwu S (2021) Fabrication of Nanostructured Cadmium Selenide

Thin Films for Optoelectronics

Applications. Front. Chem. 9:661723.

doi: 10.3389/fchem.2021.661723
There is lot of research work at enhancing the performance of energy conversion and energy storage devices such as solar cells, supercapacitors, and batteries. In this regard, the low bandgap and a high absorption coefficient of CdSe thin films in the visible region, as well as, the low electrical resistivity make them ideal for the next generation of chalcogenide-based photovoltaic and electrochemical energy storage devices. Here, we present the properties of CdSe thin films synthesized at temperatures (below $100^{\circ} \mathrm{C}$ using readily available precursors) that are reproducible, efficient and economical. The samples were characterized using XRD, FTIR, RBS, UV-vis spectroscopy. Annealed samples showed crystalline cubic structure along (111) preferential direction with the grain size of the nanostructures increasing from 2.23 to $4.13 \mathrm{~nm}$ with increasing annealing temperatures. The optical properties of the samples indicate a small shift in the bandgap energy, from 2.20 to $2.12 \mathrm{eV}$ with a decreasing deposition temperature. The band gap is suitably located in the visible solar energy region, which make these CdSe thin films ideal for solar energy harvesting. It also has potential to be used in electrochemical energy storage applications.

Keywords: CdSe, thin films, chemical bath deposition, optical properties, energy materials, electrochemical energy storage

\section{INTRODUCTION}

Cadmium Selenide is an n-type direct bandgap II-VI semiconducting material. The bulk bandgap energy of $1.74 \mathrm{eV}$ at $300 \mathrm{~K}$ is very close to the NIR, which can be increased through a variety of processes (Acharya et al., 2010). The reported molecular weight is $191.37 \mathrm{~g} / \mathrm{mole}$ in which Cd is $58.74 \%$ and Se is $41.26 \%$ and has a dark red color in appearance (Acharya et al., 2010). During the last decade, extensive research work has been carried out on the II-VI group semiconductors such as $\mathrm{CdSe}, \mathrm{CdTe}, \mathrm{ZnSe}$, and CdS thin films due to their potential applications in optoelectronic devices. CdSe is an important member of this group of compounds because of its extensive use in different fields such as biomedical technology, solar cell technology 
(Pal et al., 1990; Gruszecki and Holmström, 1993), chemical sensing, thin film transistors (Hossain et al., 2019), photoconductors (Shimizu et al., 1971), acousto-optical devices (Bonello and Fernandez, 1993), gas sensors (Smyntyna et al., 1994), photoelectrochemical devices (Naushad et al., 2018), and photoreceptors. Different fabrication techniques have been reported to grow thin films of CdSe which includes the chemical bath deposition technique (Erat et al., 2008; Hernandez-Perez et al., 2008), molecule beam epitaxy (Samarth et al., 1989), electrodeposition (Sturgis, 2015), spray pyrolysis, successive ionic layer adsorption and reaction (Pathan et al., 2003), thermal evaporation (Baban and Rusu, 2003; Shreekanthan et al., 2003), and MOVCD (Chae et al., 2006).

Extensive research work has been done on the structural, electrical, and optical properties of CdSe thin films, but it still demands further research for a variety of reasons. Although, semiconducting CdSe can be utilized for application in solar cells (Rickus, 1982) electrochemical energy storage devices (Joonho Bae and Dong Kee, 2016), and other optoelectronic devices (Fan et al., 2015) their competitiveness and use in such devices demand a fabrication method which is both reliable, cost-effective, and scalable. Many laboratory-based researches abound but very little has been done to transition from basic or fundamental research to develop reliable prototype devices and possible commercialization (Zhao et al., 2012). Most times, these basic researches are conducted with materials and apparatuses that are cost-intensive and the condition of use of such appliances are outrageously high, like very high temperatures (Chan et al., 2005), ultra-high vacuum (Bernard et al., 2004), etc. These extreme fabrication conditions can be a big challenge when transitioning from laboratory to industry. Therefore, there is an urgent need for reliable techniques that will allow for easy control of different parameters or the deposition conditions and to tune and optimize the properties of CdSe thin films to make them more efficient for utilization and application in devices.

The chemical bath deposition technique (CBD) (Chikwenze and Ezugwu, 2015; Ike et al., 2019) is considered as the most suitable technique for the fabrication of semiconducting CdSe thin films owing to many advantages such as costeffective, homogeneous films, simple, large area deposition and its ability to get good thin films using parameters that can be easily controlled.

The influence of bath temperature on structural, morphological, chemical composition and optical properties of CdSe thin films was investigated by Vishwakarma et al. (2013). Thickness dependent variation in structural, optical and electrical properties of CdSe thin films was also studied (Choudhary and Chauhan, 2019). Effect of deposition potential on the morphological and optical properties was studied (Bai et al., 2020). Crystal structure, surface profile and optical properties of CdSe thin films deposited at different bath temperatures was also investigated ( $\mathrm{Li}$ et al., 2018). But the effect of bath temperatures also effect of annealing on structural, morphological and optical properties has not been investigated.

In this paper, a low-temperature fabrication of nanostructured thin films of CdSe via simple, cost and time effective CBD method is reported. Special attention has been paid to the preparation of CdSe thin films by keeping the temperature below $100^{\circ} \mathrm{C}$. After successful preparation of CdSe thin films, their structural, interfacial, and optical properties have been studied. Effect of substrate temperatures and annealing temperatures on the optoelectronic and structural properties of these films are explored. It has been found that the CdSe thin films absorb visible light (within the wavelength range of 563$585 \mathrm{~nm}$ ), which corresponds to the bandgap energy of 2.12 $2.20 \mathrm{eV}$. While a high vacuum sputtered CdSe thin film exhibited NIR bandgap energy, our low-cost fabrication method yields films that can harvest visible light energy for photovoltaic application. Furthermore, the SEM study has revealed particles agglomeration, and increase in particle size from 230 to $680 \mathrm{~nm}$ with an increasing deposition temperature which is in conformity with the temperature dependence of the particle size evolution report in the literature (Rosly et al., 2021). This ability to deposit CdSe semiconductor thin films at low temperatures below the glass transition temperatures of many flexible substrates has the potential to open new perspectives for studying, in a reliable manner the electronic and optical property of semiconducting thin films on these substrates.

\section{EXPERIMENTAL DETAILS}

\section{Sample Preparation}

CdSe thin films can be prepared by using several precursors of $\mathrm{Cd}$ and Se. In this work we used cadmium acetate dehydrate $\left[\mathrm{Cd}\left(\mathrm{CH}_{3} \mathrm{COO}\right)_{2} .2 \mathrm{H}_{2} \mathrm{O}\right]$ (99\% purity), selenium powder (Se) (99.9\% purity), Triethanolamine (TEA) $\left[\mathrm{N}\left(\mathrm{CH}_{2} \mathrm{CH}_{2} \mathrm{OH}\right)_{3}\right](98 \%$ purity, sodium sulphite $\left(\mathrm{Na}_{2} \mathrm{SO}_{3}\right)$ (98\% purity) and $25 \%$ ammonium hydroxide $\left(\mathrm{NH}_{4} \mathrm{OH}\right)$ as the precursors. Substrate cleaning is vital in the fabrication of thin films to enhance the adhesion of the films. The glass slide substrates were first washed with detergent and water, kept in hydrochloric acid (a suitable amount of HCL is taken in which commercially available glass slides were immersed vertically) for $2 \mathrm{~h}$, washed in deionized water and then rinsed in acetone. Ultrasonic cleaning in deionized water for 15 min was subsequently carried out as the last step in our cleaning process. Well-cleaned glass substrates were placed in a hot oven for a few minutes to dry.

Prior to the deposition of CdSe thin films, aqueous solution of the various precursors was prepared. Cadmium acetate dihydrate $\left[\mathrm{Cd}\left(\mathrm{CH}_{3} \mathrm{COO}\right)_{2} .2 \mathrm{H}_{2} \mathrm{O}\right]$ serves as the source of $\mathrm{Cd}$ ions while freshly prepared sodium selenosulfate $\left(\mathrm{Na}_{2} \mathrm{~S}_{\mathrm{e}} \mathrm{SO}_{3}\right)$ was used as the source of Se ions. For preparing its solution, $1.89 \mathrm{~g}$ of sodium sulphite $\left(\mathrm{Na}_{2} \mathrm{SO}_{3}\right)$ was dissolved in $15 \mathrm{ml}$ of water. Then $1.84 \mathrm{~g}$ of selenium (Se) was added to this solution. The solution was kept at the temperature of $85^{\circ} \mathrm{C}$ for $5 \mathrm{~h}$ with constant magnetic stirring. A fresh solution of sodium selenosulfate is required because the salt is unstable if allowed to stand for a long time in solution. Figure 1a shows the stages involved in the growth of CdSe thin films in which 0.5 mol. $\mathrm{L}^{-1}$ of cadmium acetate dihydrate was first dissolved in a beaker with $10 \mathrm{~mL}$ of water. The solution was subsequently placed in a magnetic stirrer set at a low stirring speed. Five $\mathrm{ml}$ of triethanolamine (TEA) which serves as the complexing agent was introduced to the solution dropwise while stirring. To stabilize the $\mathrm{pH}$ of the solution, $10 \mathrm{ml}$ 


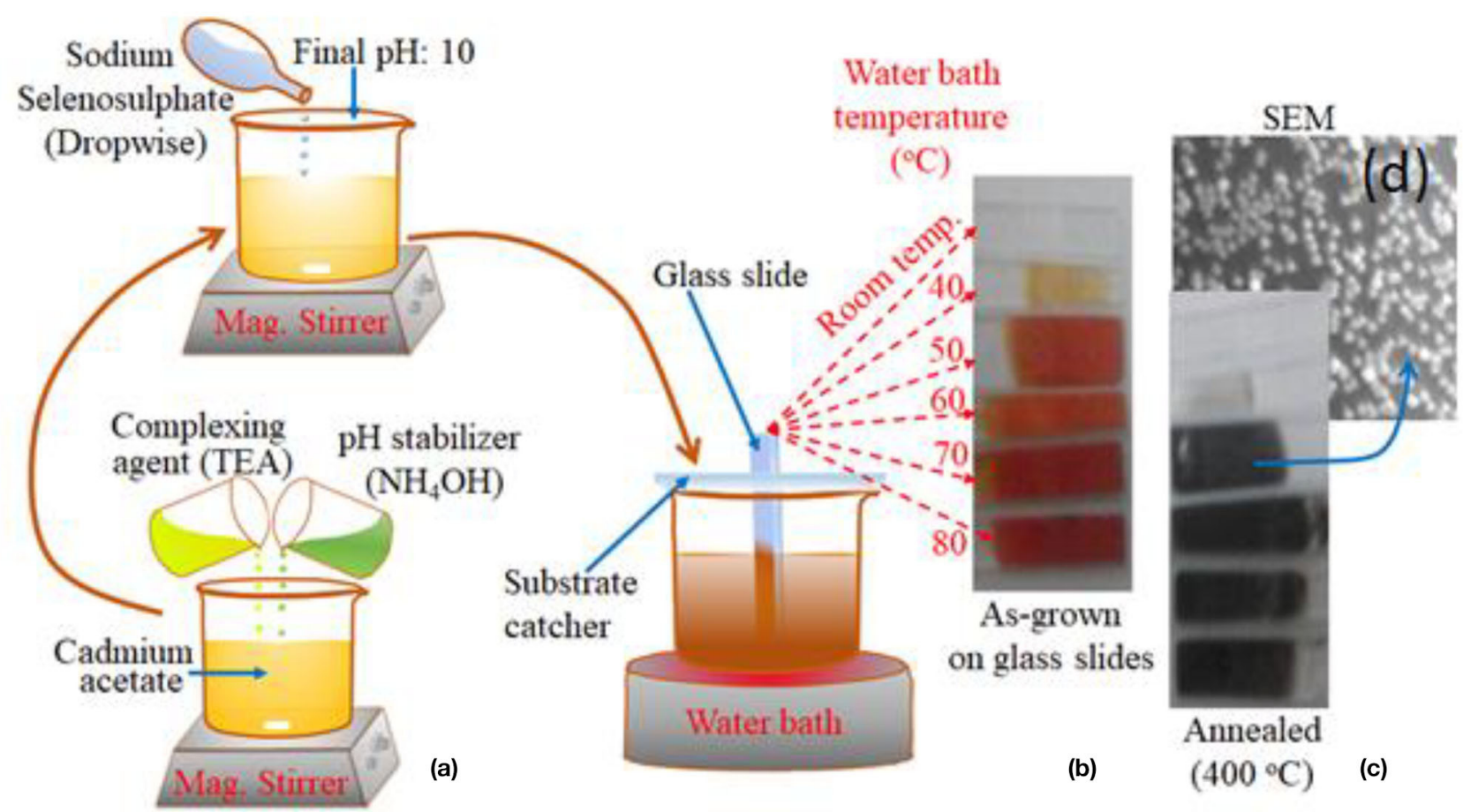

FIGURE 1 | (a) The stepwise procedure for the fabrication of CdSe thin films by chemical bath deposition method using the complexing agent, pH stabilizer and freshly prepared Se salt. (b) Picture of five samples of CdSe thin film deposited on the glass substrate at different deposition bath temperatures. (c) Picture of the samples of CdSe annealed at $400^{\circ} \mathrm{C}$, and (d) SEM image of CdSe sample.

of $25 \%$ aqueous ammonia was added into the beaker, followed by thorough mixing with the magnetic stirrer. Next, $15 \mathrm{ml}$ of freshly prepared sodium selenosulfate solution was added, dropwise, with the $\mathrm{pH}$ of the solution kept constant at $10 \pm 0.5$.

A homemade substrate catcher was used to place the substrate centrally in the solution as shown in Figure 1a. Thin films of CdSe was deposited on the glass substrate for $6 \mathrm{~h}$ at fixed temperature, which was maintained by a water bath apparatus. This procedure was repeated to grow other samples at different temperatures of $40,50,60,70$, and $80^{\circ} \mathrm{C}$, respectively. A new precursor solution was used for each tested temperature. A control sample at room temperature was also deposited as shown in Figure 1b. After the deposition, the slide was washed with a fountain of deionized water to eliminate residues before drying them in air. It is observed that films of CdSe which are prepared at room temperature were colorless but as the bath temperature increased colorless CdSe thin film changed gradually to orange and then to dark red as shown in Figure $\mathbf{1 b}$.

To obtain thin films with good crystallinity, the samples were annealed in a tube furnace at temperatures of 100,200 , and $400^{\circ} \mathrm{C}$ for $2 \mathrm{~h}$. It was observed that after annealing, the color of the CdSe films turned to dark black consistently with previous reports (Ali et al., 2013). The set of samples that were annealed at $400^{\circ} \mathrm{C}$ are depicted in Figure 1c. Typical SEM image of annealed samples shown in Figure 1d indicates that the thin films comprised of well-nucleated nanoparticles.

\section{Characterization}

The structural and optical characteristics of these films were investigated as a function of the annealing temperatures. Structural and phase analysis of CdSe thin films were done by using Rigaku Geiger flux instrument with $\mathrm{Cu} \mathrm{K}_{\alpha}$ radiations having wavelength $1.54051 \AA$. The XRD patterns of these films were obtained in angular range $(2 \theta)$ from $10^{\circ}$ to $80^{\circ}$ with a step size of $0.05^{\circ}$. FTIR transmissions spectra of CdSe thin films synthesized at different bath temperatures and annealed at $400^{\circ} \mathrm{C}$ were obtained with Perkin-Elmer FTIR Spectrometer. The spectra were taken at room temperature in the range of 400-4,000 $\mathrm{cm}^{-1}$. The Surface morphology of the thin films was examined with a scanning electron microscope (Jeol: JSM-6510LV), which was operated at $25 \mathrm{kV}$. The optical properties were investigated with Perkin Elmer Lambda 19 Spectrometer operated at the wavelength range from 300 to $800 \mathrm{~nm}$.

The chemical composition of CdSe thin films and interface structure for interdiffusion between CdSe films and glass substrate were studied using Rutherford Backscattering Spectroscopy (RBS). The RBS was carried out by utilizing a $5 \mathrm{MeV}$ pelletron tandem accelerator. The accelerator generated a mono energetic $\mathrm{He}^{++}$ions beam, which has energy $2.084 \mathrm{MeV}$ with a beam current of $28 \mathrm{nA}$. The RBS data simulation was carried out by using ion beam analysis software (SIMNRA). 


\section{RESULTS AND DISCUSSION}

\section{Formation of CdSe}

The deposition of CdSe thin film using CBD technique involves controlled precipitation of the ions in solution and subsequent nucleation of the resulting species on the substrates such as the microscopic glass slides used in this study. At optimum reaction temperature, the precipitation of CdSe occurs when the ionic product of reactants becomes greater than their solubility product. However, if the conditions for precipitation are not fully satisfied the resulting solid phase dissolves in the solution and ultimately resulting in a depleted or no deposition (Ezugwu et al., 2009; Deshpande et al., 2013a; Onyia, 2017).

The $\mathrm{pH}$ of the solution, the deposition temperatures and the complexing agent concentration are the key parameters that control the concentration of the free metal ions in CBD setups. By controlling the release of $\mathrm{Cd}^{2+}$ and $\mathrm{Se}^{2-}$ ions, one can obtained uniform thin films at optimum deposition conditions. In this work, triethanolamine (TEA) was used as the complexing agent to regulate the hydrolysis of cadmium metal ion in the solution. TEA was added dropwise to the cadmium salt to initiate a slow reaction in the solution and subsequent formation of complex $\mathrm{Cd}$ salt as shown below:

$$
C d^{2+}+T E A \rightarrow[C d(T E A)]^{2+}
$$

Ammonia was dissolved in water to provide $\mathrm{OH}^{-}$ions which forms part of the reacting species:

$$
\mathrm{NH}_{3}+\mathrm{H}_{2} \mathrm{O} \rightleftharpoons \mathrm{NH}_{4}^{+}+\mathrm{OH}^{-}
$$

The overall chemical reaction for the deposition of thin films of CdSe can be described by the following chemical equation.

$$
\begin{aligned}
& {[\mathrm{Cd}(\mathrm{TEA})]^{2+}+\mathrm{Na}_{2} \mathrm{SeSO}_{3}+2 \mathrm{OH}^{-} \rightarrow \mathrm{CdSe}+\mathrm{Na}_{2} \mathrm{SO}_{4}} \\
& +\mathrm{TEA}+\mathrm{H}_{2} \mathrm{O}
\end{aligned}
$$

To enhance the deposition rate and tune the properties of the resulting thin films of CdSe, the deposition was carried out at different temperatures by placing the solution bath on a regulated water bath. Six samples of films were fabricated on glass substrates at different temperatures of $40,50,60,70,80^{\circ} \mathrm{C}$ and a control sample at room temperature.

\section{Structural Studies}

CdSe has two structural polymorphs, the crystal structure appearing as Wurtzite or cubic, zinc blende-type (Xia et al., 2010). A previous report (Kale and Lu, 2015) show that the thin films of CdSe deposited on a glass substrate by CBD is either cubic or hexagonal. In our specific case, the XRD pattern of the films deposited at different bath temperatures shown in Figure 2 revealed that the samples are mostly amorphous

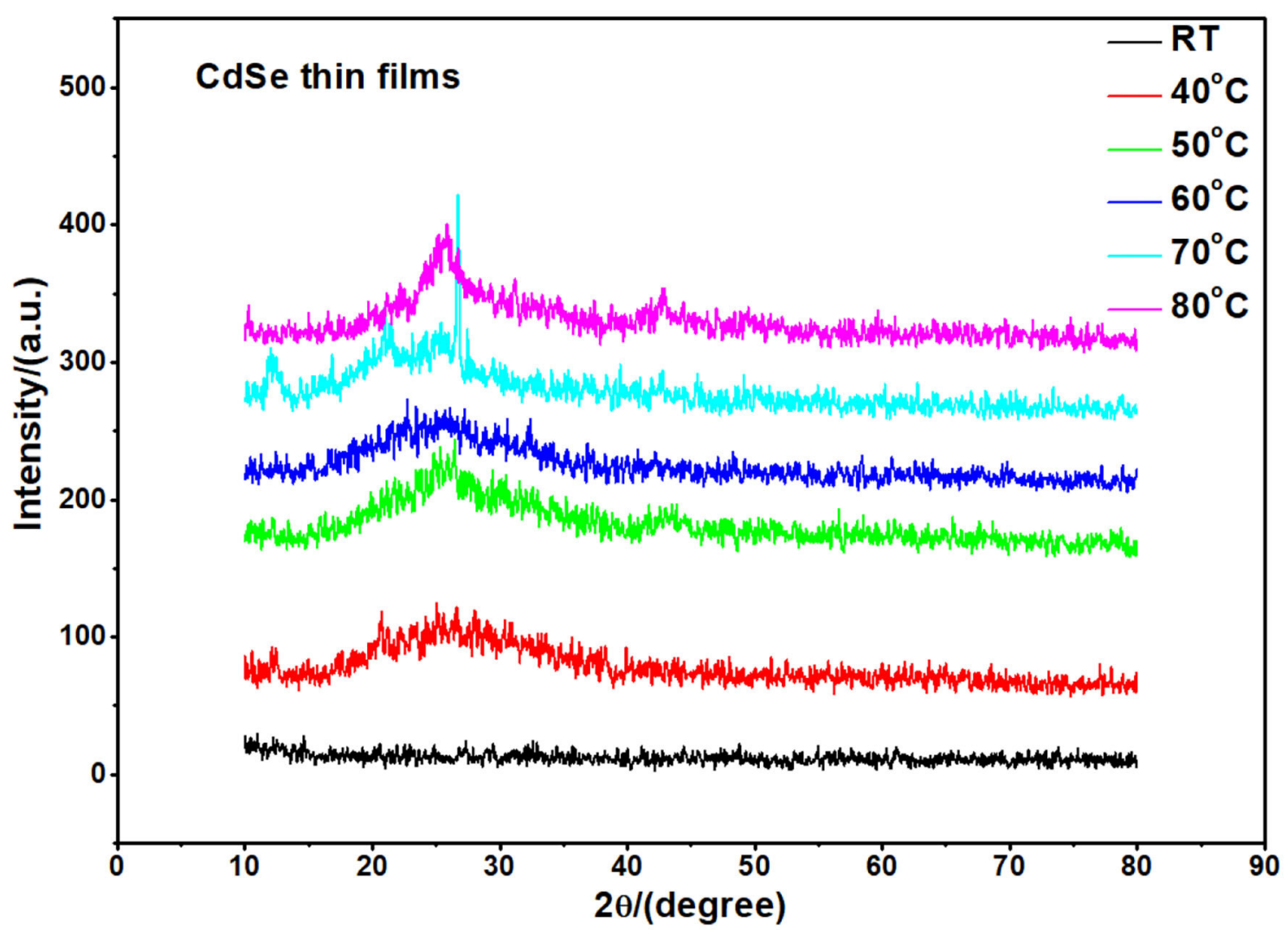

FIGURE 2 | XRD pattern of as-deposited thin films of CdSe fabricated at different bath temperatures. The samples appear amorphous in structure. 
in nature. However, as the deposition temperature increases, a small-broadened peak starts to appear. The broad XRD peak around $25.5^{\circ} \mathrm{C}$ is clearly observed for the thin films synthesized at $80^{\circ} \mathrm{C}$. It appears that the best bath temperatures for the thin film deposition are 70 and $80^{\circ} \mathrm{C}$. Hence, the sample deposited at $80^{\circ} \mathrm{C}$ will be investigated further. It was observed that the thermal treatment of the samples helps to induce structural modification from amorphous to crystalline, as shown in Figure 3. It is clear from these results that the CdSe films deposited at $80^{\circ} \mathrm{C}$ and annealed at 100,200 , and $400^{\circ} \mathrm{C}$ are polycrystalline in nature and have a cubic structure with intense (111) reflection peaks. Figure 3 also shows that as annealing temperature increase from 100 to $400^{\circ} \mathrm{C}$ the crystallinity also increases. However, the sample which was annealed at $450^{\circ} \mathrm{C}$ showed an increased broadening of the (111) diffraction peak. This is possibly due to a decrease in the crystallite size at this elevated annealing temperature (see Table 1). When CdSe thin films are annealed at a temperature of $450^{\circ} \mathrm{C}$, chemical degradation can occur with a possible conversion from CdSe to the oxide, $\mathrm{CdO}$ (Mahato and Kar, 2017).

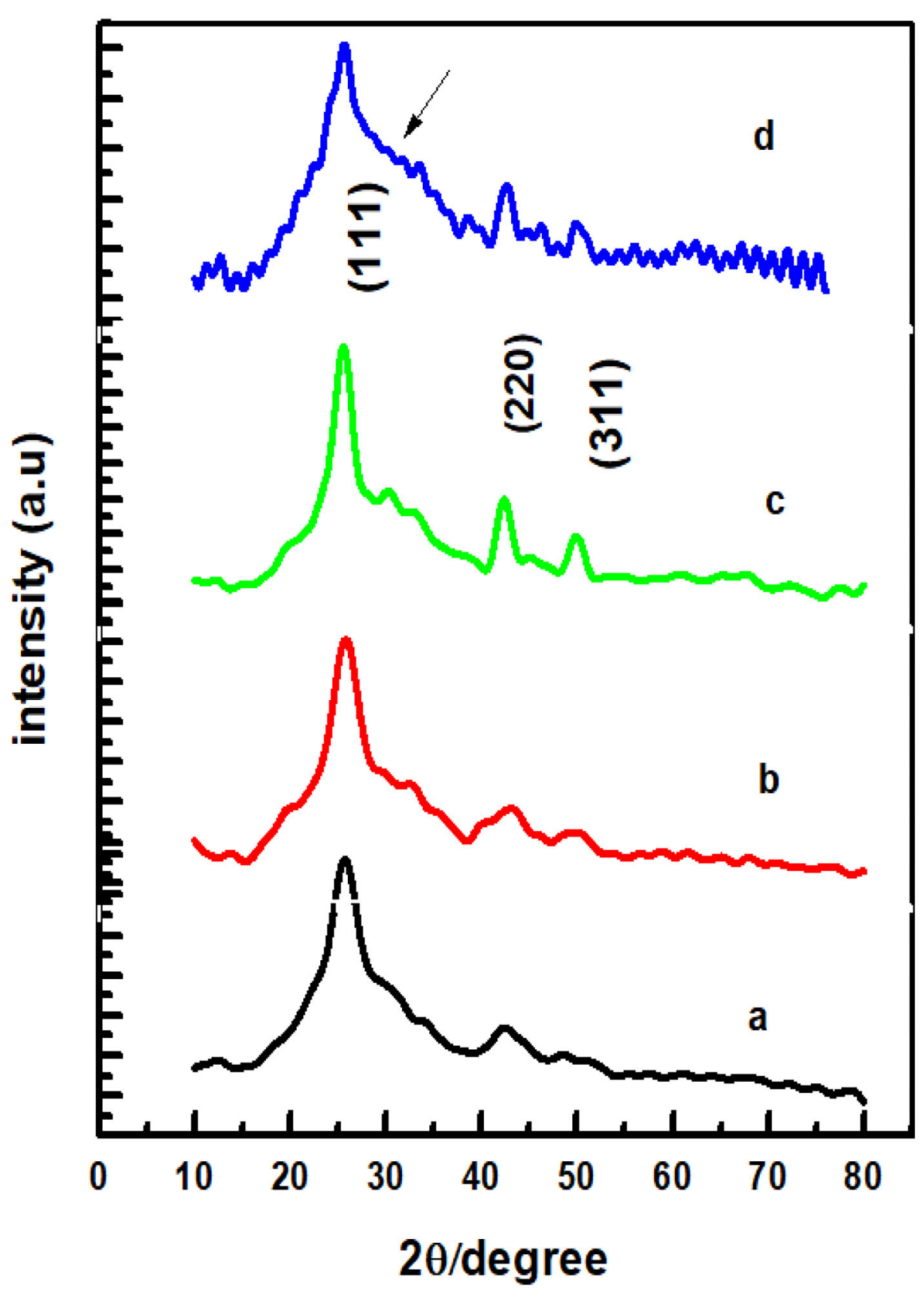

FIGURE 3 | XRD patterns of CdSe thin films deposited at bath temperature of $80^{\circ} \mathrm{C}$ and annealed in air at (a) $100^{\circ} \mathrm{C}$, (b) $200^{\circ} \mathrm{C}$, (c) $400^{\circ} \mathrm{C}$, and (d) $450^{\circ} \mathrm{C}$. 
The crystalline size of the nanocrystallites was calculated by using Scherrer's formula given below.

$$
D=\frac{k \lambda}{\beta \cos \theta}
$$

where " $D$ " is crystallite size, $k$ is constant having value $0.9, \lambda$ is the wavelength of X-rays, $\beta$ is full width at half maximum, and $\theta$ is Bragg's angle. Dislocation density $(\delta)$ and microstrain $(\varepsilon)$ of CdSe thin films were also calculated with the following equations:

$$
\begin{array}{r}
\delta=\frac{1}{D^{2}} \\
\varepsilon=\frac{\beta \cos \theta}{4}
\end{array}
$$

The values of the Lattice constant (a), d spacing, FWHM ( $\beta$ ), grain size $(\mathrm{D})$, dislocation density $(\delta)$, and microstrain $(\varepsilon)$ calculated from the XRD results in Figure 3 are reported in Table 1. The results show that as the annealing temperatures of thin films of CdSe increases the full width at half maximum, FWHM $(\beta)$ of the films decreases. Consequently, the grain size of the samples increases from 2.23 to $4.13 \mathrm{~nm}$ with annealing temperatures. However, the dislocation density $(\delta)$ and microstrain $(\varepsilon)$ of the films decreases with the increase in the annealing temperature. The intensity of the peaks also increases by increasing the annealing temperature.

\section{FTIR Studies}

Fourier transform spectroscopy is used to investigate vibrational modes of different finctional groups. Figure 4 shows the FTIR pattern of thin films of CdSe deposited at bath temperatures of (a) $50^{\circ} \mathrm{C}$, (b) $70^{\circ} \mathrm{C}$, (c) $80^{\circ} \mathrm{C}$, and (d) film synthesized at $80^{\circ} \mathrm{C}$ and then annealed at $400^{\circ} \mathrm{C}$. The broad peak observed at $3,460 \mathrm{~cm}^{-1}$ is assigned to $\mathrm{O}-\mathrm{H}$ stretching and is due to the presence of a small quantity of water molecules in CdSe thin films. The peak at 2,990 $\mathrm{cm}^{-1}$ is assigned to $\mathrm{C}-\mathrm{H}$ stretching of $\mathrm{CH}_{2}$ group (Ravindranadh et al., 2013). The peak observed at $668 \mathrm{~cm}^{-1}$ is the fingerprint spectral peak of CdSe (Rani, 2014). This band confirmed the occurrence of a vibrational mode of CdSe lying between 400 and $700 \mathrm{~cm}^{-1}$ (Ali et al., 2013). Figure 4 also revealed that the peak which is due to $\mathrm{O}-\mathrm{H}$ stretching shows decreasing \% $\mathrm{T}$ intensities by increasing the deposition temperatures from 50 to $80^{\circ} \mathrm{C}$ and by annealing at $400^{\circ} \mathrm{C}$.

\section{Surface Morphology}

Scanning electron microscope (SEM) which provides an appropriate way to study the surface morphology of thin films was used to examine the surface morphology of our samples. SEM gives information about grain size, roughness, and surface morphology of thin films. Figures 5a-c show SEM micrographs and surface morphology of thin films of CdSe synthesized at different bath temperatures of 50 , 70 , and $80^{\circ} \mathrm{C}$. From the SEM micrograph of these films, it is evident that films adhered well to the surface of the substrate and consist of many small grains that are sparsely distributed. However, the density of the nanoparticles appears to increase with the increasing temperature of the deposition bath. Figure 5d shows that post-deposition thermal annealing has significant effects on the morphology of our CdSe thin films. A comparison of Figures 5a,d indicates that the morphology of the sample annealed at $400^{\circ} \mathrm{C}$ is dense and compact. This can be attributed to the increase in the activation energy needed for intergrain diffusion, leading to smaller grains joining to form large grains, which in turn increases the size of the nanoparticles as shown in Figure 5e.

Figure 5e shows that the particle size also depends on the deposition temperature, increasing from $230 \mathrm{~nm}$ at $50^{\circ} \mathrm{C}$ deposition temperature to as much as $680 \mathrm{~nm}$ at $80^{\circ} \mathrm{C}$. We observe a significant increase of the size of nanoparticles for the samples deposited at $80^{\circ} \mathrm{C}$ when compared to the two samples deposited at lower bath temperatures of 50 and $70^{\circ} \mathrm{C}$. This observation suggests that $80^{\circ} \mathrm{C}$ is the ideal bath temperature in which nucleation and growth of $\mathrm{Cd}$ and Se ions on the substrates can proceed favorably to form nanoparticles. Once the initial nuclei are attached on the substrate, further growth from the impinging ions in the condensation is expected to proceed via the Volmer-Weber growth pattern, leading to the observed increase in both the density and size of the nanoparticles (Apeh et al., 2019).

\section{Optical Transmission Analysis of Thin Films of CdSe}

Ultraviole-tvisible (UV-vis) spectroscopy is an optical technique used to investigate optical aborption/transmission of the sample. Figure 6 represent transmittance spectra of CdSe thin films

\begin{tabular}{|c|c|c|c|c|c|c|c|}
\hline $\begin{array}{l}\text { Materials } \\
\text { with } \\
\text { annealed } \\
\text { temperatures }\end{array}$ & $\begin{array}{c}2 \theta \\
\text { (degree) }\end{array}$ & (hkl) & $\begin{array}{l}\text { Lattice } \\
\text { constant } \\
\text { (a) (Å) }\end{array}$ & $\begin{array}{c}\text { FWHM } \\
(\beta) \\
\text { (radian) }\end{array}$ & $\begin{array}{l}\text { Grain } \\
\text { size }(D) \\
(n m)\end{array}$ & $\begin{array}{c}\text { Dislocation } \\
\text { density }(\delta) \times \\
10^{16} \\
\left(\text { lines } / \mathrm{m}^{2}\right)\end{array}$ & $\begin{array}{c}\text { Micro } \\
\text { strain }(\varepsilon) \\
\times 10^{-3}\end{array}$ \\
\hline $\mathrm{CdSe}\left(100^{\circ} \mathrm{C}\right)$ & 25.588 & 111 & 6.1297 & 0.0638 & 2.23 & 20.13 & 15.55 \\
\hline $\mathrm{CdSe}\left(200^{\circ} \mathrm{C}\right)$ & 25.588 & 111 & 6.2094 & 0.0540 & 2.63 & 14.41 & 13.15 \\
\hline $\mathrm{CdSe}\left(400^{\circ} \mathrm{C}\right)$ & 25.340 & 111 & 6.0102 & 0.0343 & 4.13 & 5.84 & 8.38 \\
\hline
\end{tabular}
deposited at different bath temperatures and annealed at $400^{\circ} \mathrm{C}$.

TABLE 1 | The parameter of the CdSe structure calculated from the XRD results. 


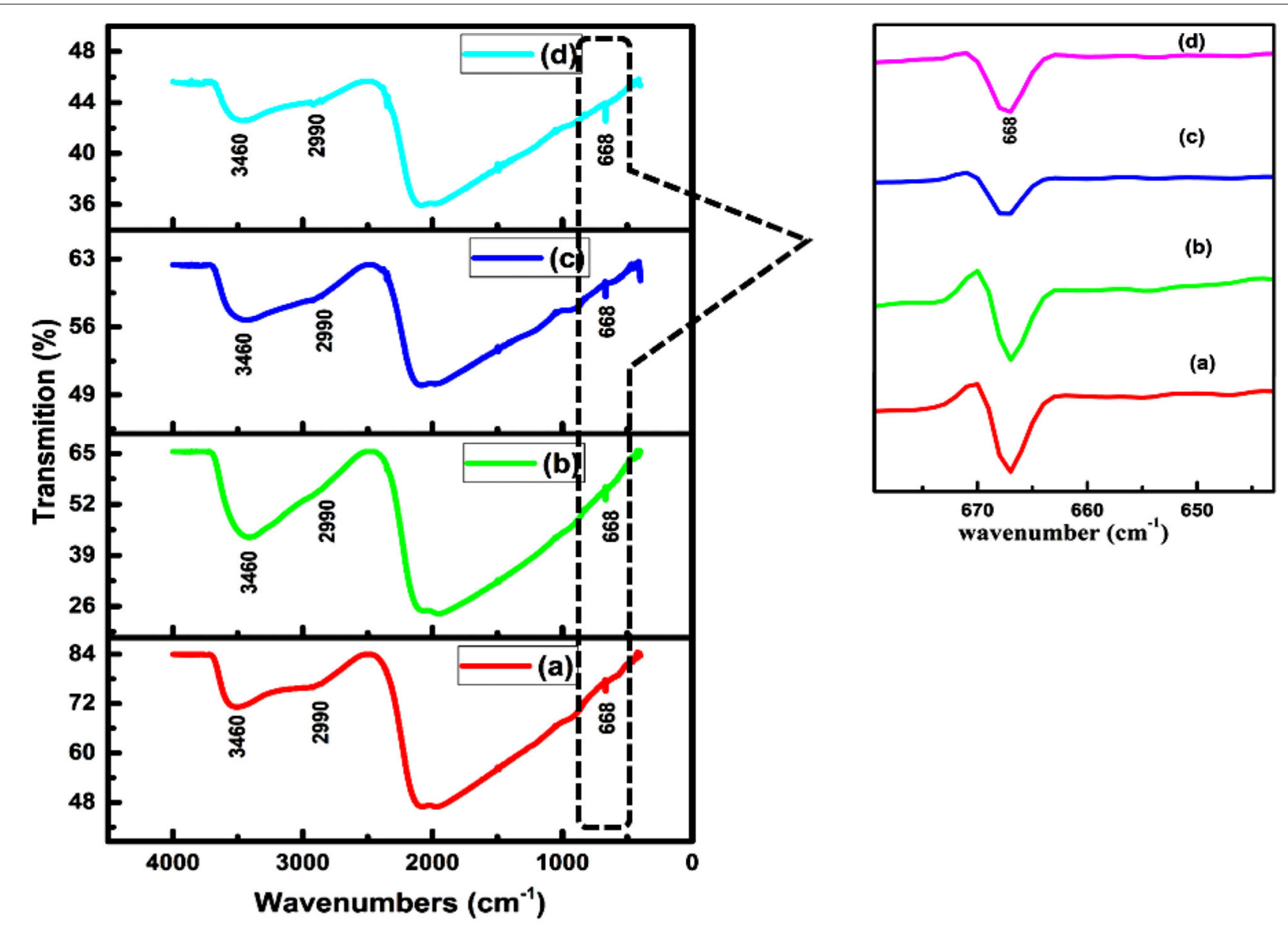

FIGURE 4 | FTIR pattern of CdSe thin films deposited at (a) $50^{\circ} \mathrm{C}$, (b) $70^{\circ} \mathrm{C}$, (c) $80^{\circ} \mathrm{C}$, and (d) annealed at $400^{\circ} \mathrm{C}$.

The figure indicates that the transmittance of thin films of CdSe is generally low, approaching $10 \%$ at maximum. The figure shows that the transmission spectra of CdSe thin films have relatively higher transmittance (>5\%) above $500 \mathrm{~nm}$ (in the visible region), and near-infrared region, $700-800 \mathrm{~nm}$. In UV region, 350$400 \mathrm{~nm}$, the transmittance of CdSe thin films decrease to a very low value $(<2 \%)$, indicative of very high absorbance in the UV region of electromagnetic radiation. The result of our UV-Vis measurements shows that the transmittance of thin films of CdSe depends on the deposition and annealing temperatures. From the graphs shown in Figure 6, the transmittance decreases as deposition temperature increases, consistently with our earlier observation that the density and compactness of the samples increase with bath temperatures. The decrease in the transmittance of CdSe samples with increasing bath temperature is also consistent with the observed color changes of the films in Figure 1, from light red to dark red, indicative of greater interdiffusion of isolated grains and particle growth increase with increasing bath temperature. The transmittance of the annealed sample is also very low as compared to the un-annealed samples. After annealing, the dark red color of the thin film of CdSe changes to dark black as shown previously in Figure 1. Besides the color changes, our SEM analysis shows that postdeposition thermal annealing increases the diffusion energy for the grains to form large particles, which leads to denser films (Jamil et al., 2012). The observed color changes from dark red to dark black, the particle growth and increased density are responsible for the huge decrease in the transmittance of our CdSe thin films.

\section{Optical Band Gap Energy of CdSe Thin Films}

Figure 7 represent the graphs of $(\alpha h \nu)^{2}$ vs. $h v$ for the thin film of CdSe deposited at different bath temperatures of 50, 70, and $80^{\circ} \mathrm{C}$ and later annealed at $400^{\circ} \mathrm{C}$. The energy bandgap of the CdSe films was determined by extrapolating the straight-line part of the plot to zero absorption making an intercept with the energy axis. The interception on the energy axis $(\mathrm{h} v)$ gives the value of the energy bandgap. Figure 7 shows that the graphs of the bandgap energy are linear over a wide range of energy, 

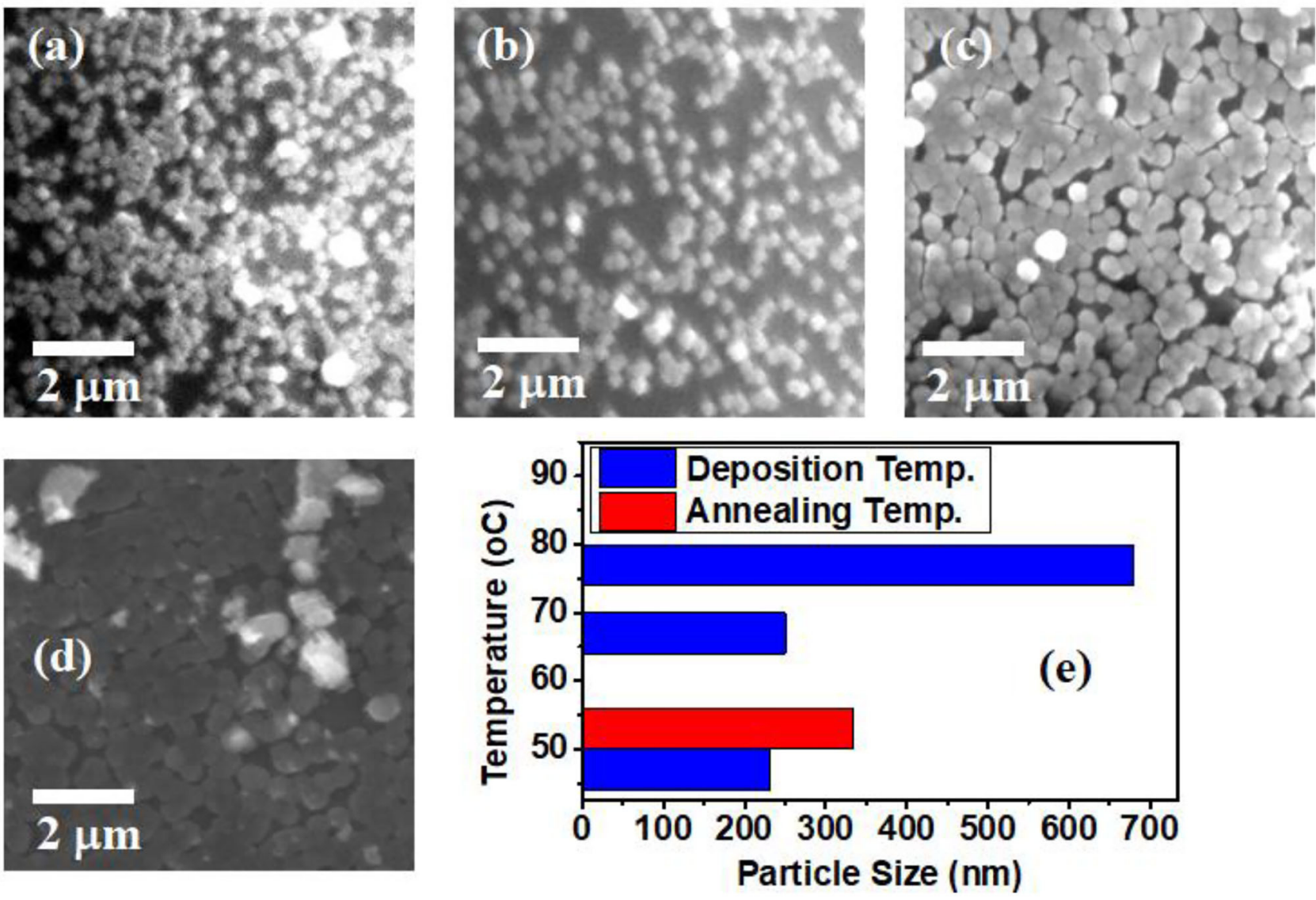

FIGURE 5 | SEM micrographs of CdSe thin films synthesized at different bath temperatures of (a) $50^{\circ} \mathrm{C}$, (b) $70^{\circ} \mathrm{C}$, (c) $80^{\circ} \mathrm{C}$, (d) $\mathrm{CdSe}$ deposited at $50^{\circ} \mathrm{C}$, and annealed at $400^{\circ} \mathrm{C}$. (e) Histogram of particles size distribution as a function of deposition and annealing temperatures.

which confirms that CdSe thin films deposited in this work, are direct bandgap semiconductor (Bernard et al., 2004). Values of the energy band gap of as-synthesized thin films of CdSe at different temperatures decrease from 2.20 to $2.12 \mathrm{eV}$ as illustrated in Table 2. El-Menyawy and Azab reported similar values for CdSe thin films prepared by the thermal evaporation technique (El-Menyawy and Azab, 2018). In our case, the bandgap energy tends to decrease with high temperature thermal annealing. In fact, after annealing at $400^{\circ} \mathrm{C}$ values of the energy band gap of CdSe thin film decreased further to $1.73 \mathrm{eV}$ in agreement with the bulk CdSe and consistently with the observed low value of the optical transmittance with thermal annealing. The decrease in the energy band gap can be attributed to the quantum confinement in CdSe thin films due to the increase in crystallite size and a decrease in defects in these films (Deshpande et al., 2013b). Visual inspection shows that the films exhibited color changes upon thermal annealing from dark red to gloomy black in conformity to earlier work reported in the literature (Daniel et al., 2017).

The average diameter of nanocrystallites can be calculated from the blue shift of band gap of CdSe, which was examined in the samples prepared at different bath temperatures, by using the following equation (Mehta et al., 2007).

$$
\Delta E_{g}=E_{g}(\text { film })-E_{g}(\text { bulk })=E_{\text {shift }}=\frac{\hbar^{2} \pi^{2}}{2 \mu R^{2}}
$$

where $\mu$ is the translation mass and is equal to $\left(m_{h}+m_{e}\right), E_{\text {shift }}$ is bandgap shift and $\mathrm{R}$ is the radius of the crystallites. By putting the observed values of band gaps of CdSe thin films from the band gap value of bulk CdSe and putting the standard values of other parameters in the above equation, the diameter of the crystallites of CdSe can be determined. The crystallite (grain) size of CdSe, which were deposited at a temperature of 50, 70, and $80^{\circ} \mathrm{C}$ are found to be $2.396,2.488$, and $2.626 \mathrm{~nm}$, respectively. These values are close to the grain sizes determined from the XRD diffractogram reported previously in Table $\mathbf{1}$.

Values of the bandgap, wavelength, band energy shift, the crystallite size and some of the other optical parameters of CdSe thin films calculated from the optical spectra are shown in Table 2. We observe that the thickness of CdSe thin films increases with increasing deposition temperature. The grain size of the films also increases and consequently the energy band gap decreases as the deposition temperature increases. 


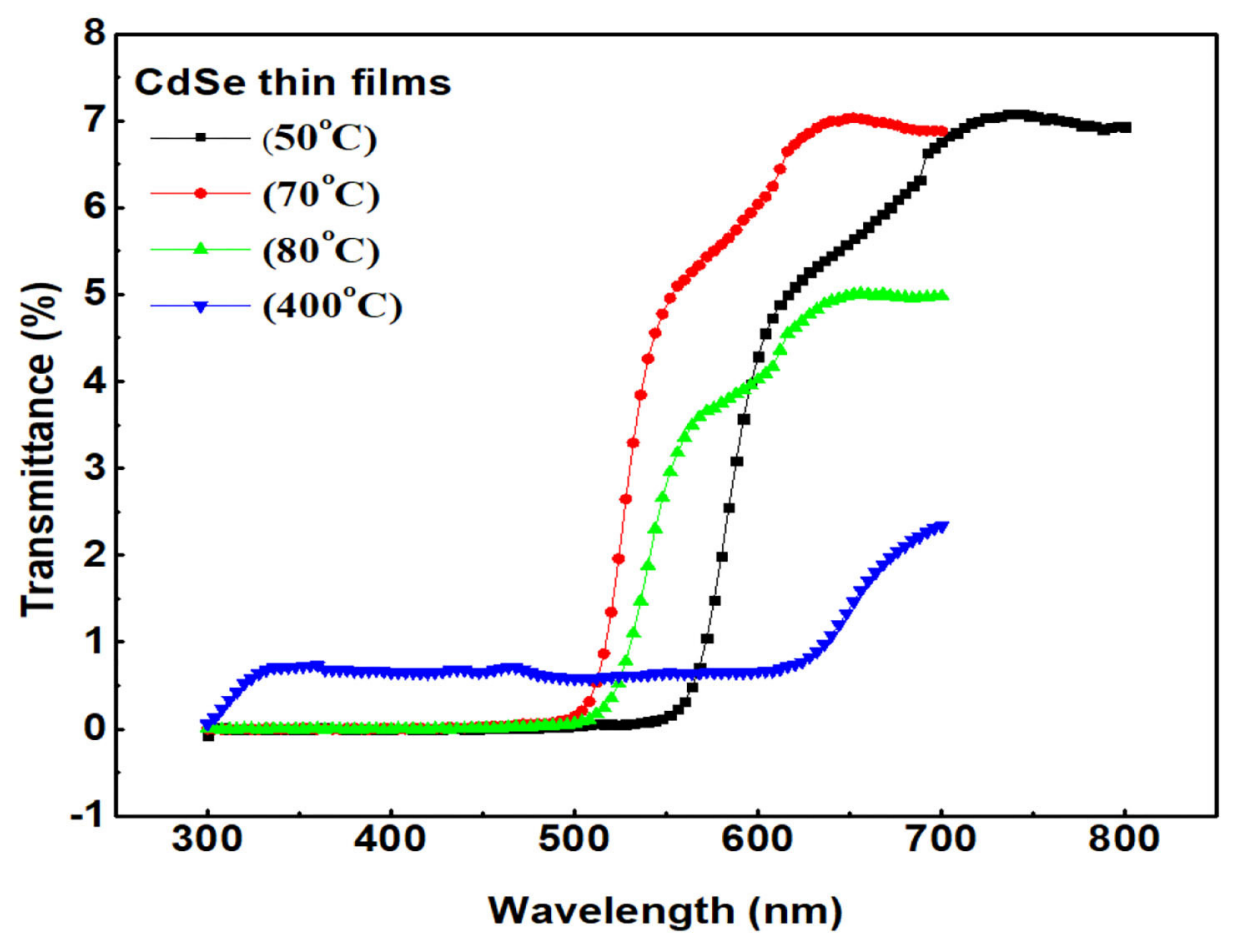

FIGURE 6 | Transmittance of thin films of CdSe synthesized at 50, 70, 80, and annealed at $400^{\circ} \mathrm{C}$.

These results show that the increase in the crystallinity of the films agrees with the SEM micrographs reported previously in Figure 5. The bandgap energies of the samples deposited at different temperatures are situated in the visible light of the solar spectrum. As such, the thin films are suitable for optoelectronic applications, especially in a solar cell where they can be used to generate photocurrent from visible light absorption.

\section{Rutherford Back Scattering Spectroscopy}

Rutherford Back Scattering Spectroscopy (RBS) is useful technique that is used to investigate the elemental profile of $\mathrm{Cd}$ and Se along the thickness of the prepared thin films. Figure 8 shows the RBS spectra of thin films of CdSe which were deposited at 70 and $80^{\circ} \mathrm{C}$, respectively. Apart from the Si signal arising from the glass substrate, two other peaks of Cadmium (Cd) and selenium (Se) are emanating from the thin films. From the RBS graph, it is seen that resolution of observed peaks for $\mathrm{Cd}$ and $\mathrm{Se}$ is very poor which is due to interdiffusion between CdSe thin films and glass substrate of these few nm thick films. As a result, the composition analysis of our sample could not be calculated with the help of RBS spectra due to the poor resolution of the $\mathrm{Cd}$ and Se peaks. However, the film thickness was calculated by the model fitting of the RBS data using software SIMNRA and has been reported in Table 2.

\section{CONCLUSIONS}

CdSe films with few nanometer thicknesses were successfully deposited by chemical bath deposition technique on the glass substrates at low temperature $\left(<100^{\circ} \mathrm{C}\right)$. The XRD results show that CdSe thin films deposited at different bath temperatures were initially amorphous in nature but after annealing at elevated temperatures, they transformed to polycrystalline thin films having cubic structure. The crystallite size increases from 2.23 to $4.13 \mathrm{~nm}$ as annealing temperatures increase from 100 to $400^{\circ} \mathrm{C}$. FTIR spectroscopy confirmed the peak of CdSe at $668 \mathrm{~cm}^{-1}$. The RBS results showed two peaks of $\mathrm{Cd}$ and Se but the exact composition could not be extracted due to the huge overlap of the peaks. SEM images of the films revealed spherical nanoparticles. By increasing the deposition and annealing temperatures, small grains agglomerate together to form larger grains, which significantly influenced the optical properties of the films. The results of UV-Vis spectroscopy of CdSe thin films showed that the transmittance decreases with increasing deposition and annealing temperatures. By increasing the deposition temperatures, the bandgap values decreased from 2.20 to $2.12 \mathrm{eV}$ and after annealing at the temperature of $400^{\circ} \mathrm{C}$ the bandgap energy further decreased to $1.73 \mathrm{eV}$. The values of the bandgap energy of the sample deposited at low temperature, below $100^{\circ} \mathrm{C}$ is located in the visible region of the solar spectrum. Hence, the films can be used in solar energy architecture as energy harvester. 

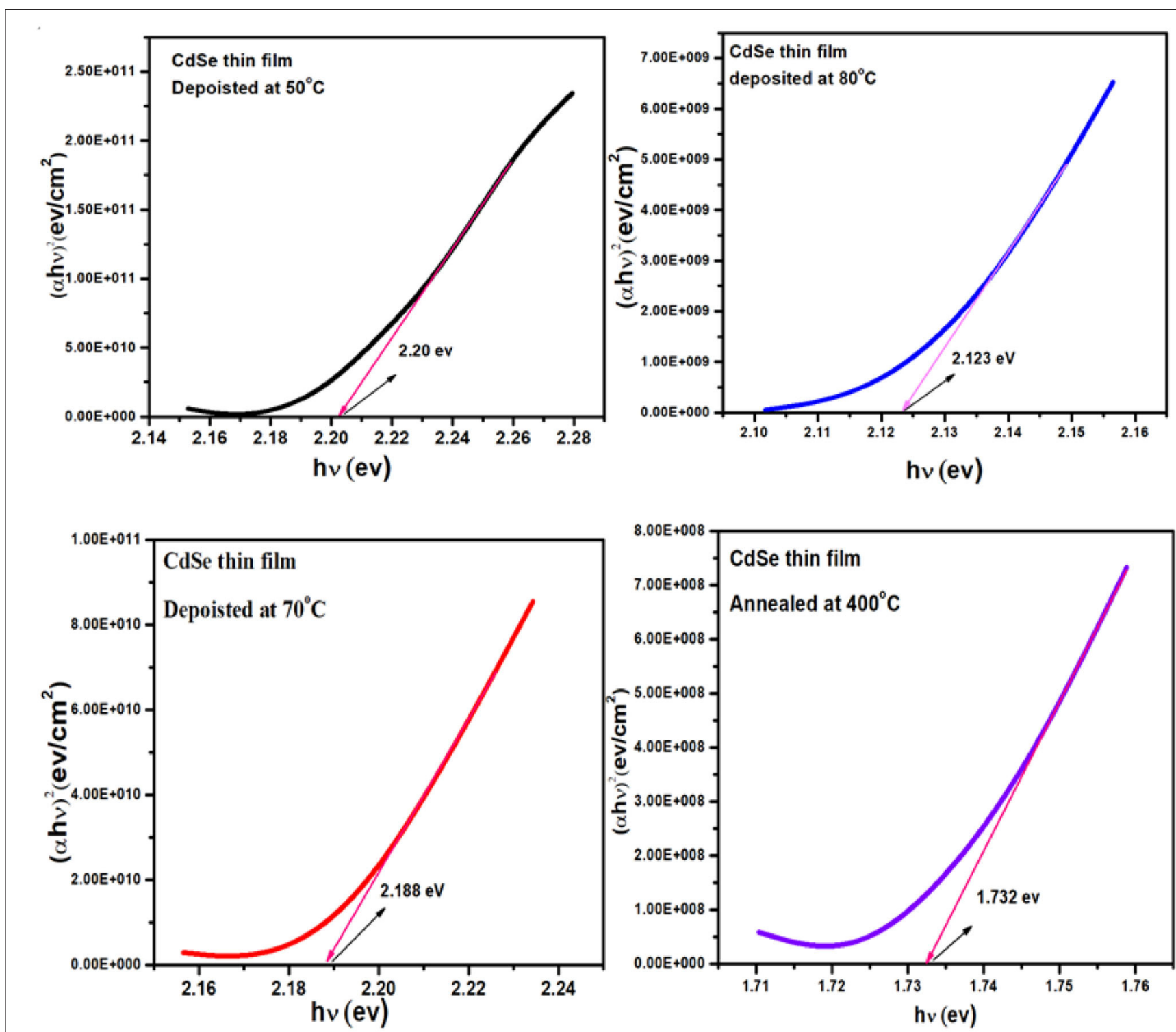

FIGURE 7 | Plot of $(\alpha h v)^{2}$ vs. (hv) of thin film of CdSe deposited at different temperatures and the film deposited at $80^{\circ} \mathrm{C}$ and annealed at $400^{\circ} \mathrm{C}$.

TABLE 2 | Optical parameters of thin films of CdSe calculated from the optical spectra.

Material with deposition

temperature
Band gap value of bulk CdSe $\left(E_{g}\right)=1.74 \mathrm{eV}$

Wavelength $(\lambda=712.6 \mathrm{~nm})$

\begin{tabular}{ccccr}
\hline Film thickness $(\mathbf{n m})$ & $\begin{array}{c}\text { Wavelength }(\lambda) \\
(\mathbf{n m})\end{array}$ & Band gap $(\mathrm{E})(\mathrm{eV})$ & $\Delta \mathrm{Eg}=\mathrm{E}_{\mathbf{g}} \mathrm{E}_{\mathbf{g}}(\mathrm{eV})$ & $\mathrm{Grain}$ size $(\mathrm{nn})$ \\
100 & 563.63 & 2.20 & 0.46 & 2.396 \\
120 & 566.72 & 2.188 & 0.44 & 2.488 \\
280 & 588.079 & 2.123 & 0.38 & 2.626
\end{tabular}



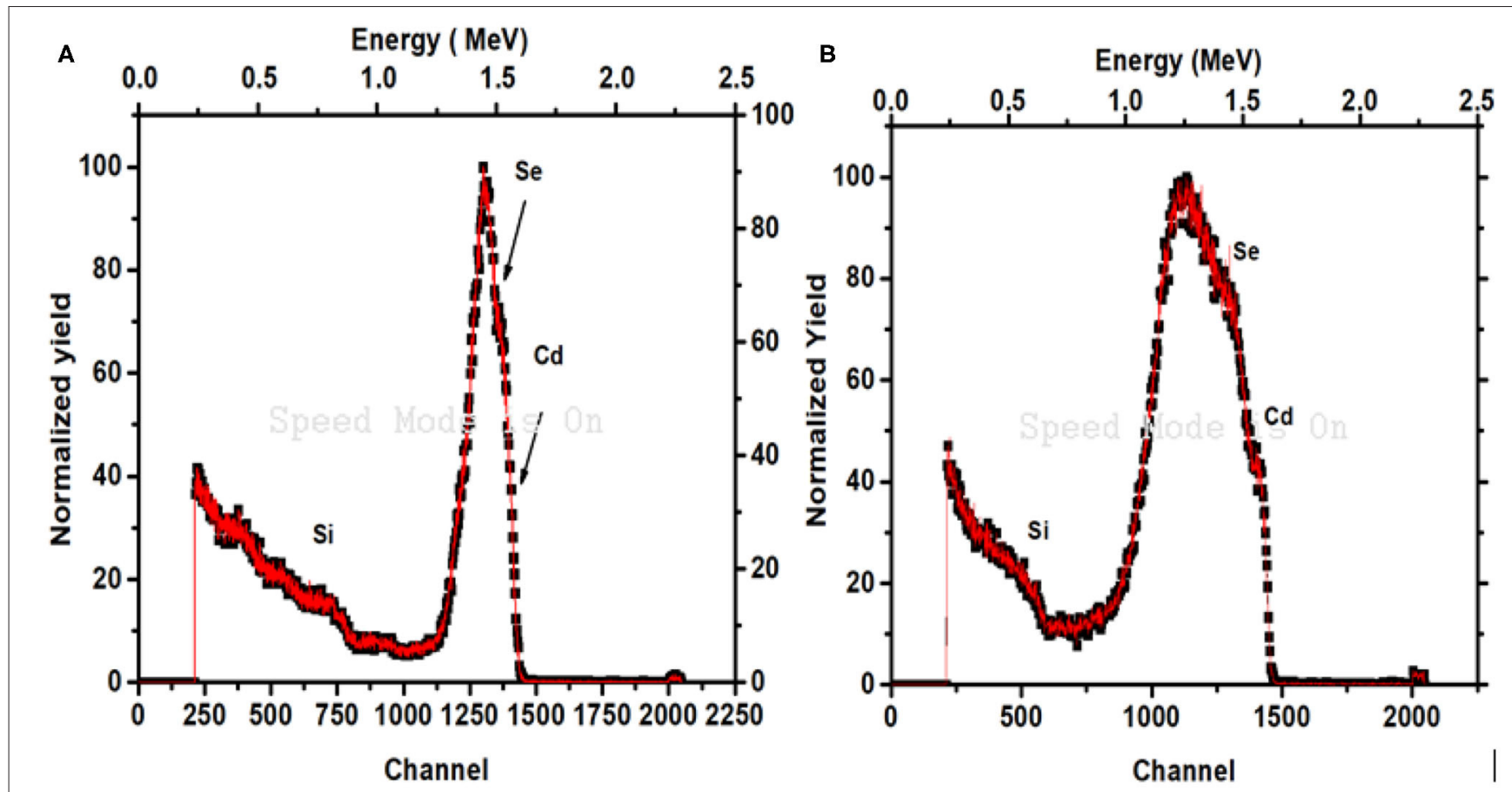

FIGURE 8 | RBS spectra of CdSe thin films deposited at (A) $70^{\circ} \mathrm{C}$, (B) $80^{\circ} \mathrm{C}$.

\section{DATA AVAILABILITY STATEMENT}

The original contributions presented in the study are included in the article/supplementary material, further inquiries can be directed to the corresponding author/s.

\section{AUTHOR CONTRIBUTIONS}

All authors listed have made a substantial, direct and intellectual contribution to the work, and approved it for publication.

\section{REFERENCES}

Acharya, A., Mishra, R., and Roy, G. (2010). Characterization of cdse/polythiophene nanocomposite by tga/dta, xrd, uv-vis spectroscopy, sem-edxa and ftir. Ar. J. Phys. 3, 195-202.

Ali, M., Syed, W. A., Zubair, M., Shah, N. A., and Mehmood, A. (2013). Physical properties of Sb-doped CdSe thin films by thermal evaporation method. Appl. Surf. Sci. 284, 482-488. doi: 10.1016/j.apsusc.2013. 07.122

Apeh, O.O., Chime, U. K., Agbo, S., Ezugwu, S., Taziwa, R., Meyer, E., et al. (2019). Properties of nanostructured $\mathrm{ZnO}$ thin films synthesized using a modified aqueous chemical growth method. Mater. Res. Express. 6:056406. doi: 10.1088/2053-1591/aadcd6

Baban, C., and Rusu, G. (2003). On the structural and optical characteristics of CdSe thin films. Appl. Surf. Sci. 211, 6-12. doi: 10.1016/S0169-4332(03)00299-X

Bai, R., Chaudhary, S., and Pandya, D.K. (2020). "CdSe thin films prepared by electrochemical deposition: The effect of deposition potential," in AIP Conference Proceedings (Bikaner: AIP Publishing LLC). doi: 10.1063/5.0001859

\section{ACKNOWLEDGMENTS}

SH greatly acknowledges the help of Experimental Physics Laboratory at National Center for Physics, Quaid-I-Azam campus, Islamabad for allowing the use of accelerator facility for RBS measurements. Help of Physics Department of Azad Jammu and Kashmir University, Muzafarabad, in Sample preperation, SEM and Optical characterizations is acknowledged. The help of the staff at Central Diagnostic Laboratory (CDL) at Physics Division, PINSTECH for the rest of the measurements are greatly appreciated.

Bernard, R., Huc, V., Reiss, P., Chandezon, F., Jégou, P., Palacin, S., et al. (2004). Ultrahigh vacuum deposition of CdSe nanocrystals on surfaces by pulse injection. J. Phys. Conden. Matt. 16:7565. doi: 10.1088/0953-8984/16/43/001

Bonello, B., and Fernandez, B. (1993). Elastic constants of CdSe at low temperature. J. Phys. Chemi. Solids 54, 209-212. doi: 10.1016/0022-3697(93)90310-N

Chae, D.-Y., Seo, K.-W., Lee, S.-S., Yoon, S.-H., and Shim, I.-W. (2006). CdSe thin films grown by MOCVD method using new single-source precursors. Bull. Korean Chem. Soc. 27, 762-764. doi: 10.5012/bkcs.2006.27.5.762

Chan, E.M., Alivisatos, A. P., and Mathies, R. A. (2005). High-temperature microfluidic synthesis of CdSe nanocrystals in nanoliter droplets. J. Am. Chem. Soc. 127, 13854-13861. doi: 10.1021/ja051381p

Chikwenze, R., and Ezugwu, S. (2015). Sulphur induced changes in the band gap energy and the transparency window of chemical bath deposited $\mathrm{ZnO}$ : $\mathrm{S}$ thin films. Chalcog. Lett. 12, 399-406. Available online at: https://chalcogen.ro/399_ Chikwenze.pdf

Choudhary, R., and Chauhan, R. (2019). Thickness dependent variation in structural, optical and electrical properties of CdSe thin films. J. Mater. Sci. 30, 5753-5759. doi: 10.1007/s10854-019-00870-8 
Daniel, N. J., Thangaraj, N., Suresh, D., and John, N. J. (2017). Electrical measurements on cadmium selenite nano composites. Int. J. Cur. Res. Rev. 9:1. doi: 10.7324/IJCRR.2017.9241

Deshpande, M., Garg, N., Bhatt, S. V., Sakariya, P., and Chaki, S. (2013b). Spectroscopy and structural study on CdSe thin films deposited by chemical bath deposition. Adv. Mater. Lett. 4, 869-874. doi: 10.5185/amlett.2013.4467

Deshpande, M., Garg, N., Bhatt, S. V., Sakariya, P., and Chaki, S. H. (2013a). Characterization of CdSe thin films deposited by chemical bath solutions containing triethanolamine. Mater. Sci. Semiconduc. Proc. 16, 915-922. doi: 10.1016/j.mssp.2013.01.019

El-Menyawy, E. M., and Azab, A. A. (2018). Optical, electrical and photoelectrical properties of nanocrystalline cadmium selenide films for photosensor applications. Optik 168:11. doi: 10.1016/j.ijleo.2018.04.056

Erat, S., Metin, H., and Ari, M. (2008). Influence of the annealing in nitrogen atmosphere on the XRD, EDX, SEM and electrical properties of chemical bath deposited CdSe thin films. Mater. Chem. Phys. 111, 114-120. doi: 10.1016/j.matchemphys.2008.03.021

Ezugwu, S., Ezema, F., Osuji, R., Asogwa, P., Ekwealor, A., and Ezekoye, B. (2009). Effect of deposition time on the band-gap and optical properties of chemical bath deposited CdNiS thin films. Optoelectr. Adv. Mater. Rapid Commun. 3, 141-144.

Fan, F., Kanjanaboos, P., Saravanapavanantham, M., Beauregard, E., Ingram, G., Yassitepe, E., et al. (2015). Colloidal CdSe1-xSx nanoplatelets with narrow and continuouslytunable electroluminescence. Nano Lett. 15:5. doi: 10.1021/acs.nanolett.5b01233

Gruszecki, T., and Holmström, B. (1993). Preparation of thin films of polycrystalline CdSe for solar energy conversion I. A literature survey. Solar Energy Mater. Solar Cells 31, 227-234. doi: 10.1016/0927-0248(93)90053-6

Hernandez-Perez, M., Aguilar-Hernandez, J., Contreras-Puente, G., VargasGarcia, J. R., and Rangel-Salinas, E. (2008). Comparative optical and structural studies of CdSe films grown by chemical bath deposition and pulsed laser deposition. Phys. E Low-Dim. Syst. Nanostru. 40, 2535-2539. doi: $10.1016 /$ j.physe.2007.10.102

Hossain, M., Siddiquee, K., Islam, O., Gafur, M., Qadir, M., and Ahmed, N. (2019). Characterization of electrodeposited ZnTe thin films. J. Optics 48, 295-301. doi: 10.1007/s12596-019-00550-0

Ike, P., Ezugwu, S., Chikwenze, R., Nwanya, A. C., Ezugwu, A., Madiba, I., et al. (2019). Efficient control of band gap energy and optical properties of titania thin films for solar cell applications. Optik 191, 1-9. doi: 10.1016/j.ijleo.2019.05.091

Jamil, Y. N., Mahmood, T. M., and Mustafa, A. N. (2012). The optical and electrical properties of Cdse thin films prepared by CBD technique. Rafid. J. Sci. 23, 116-125. doi: 10.33899/rjs.2012.29447

Joonho Bae, U.P., and Dong Kee, Y. (2016). Novel semiconducting CdSe quantum dot based electrochemical capacitors. Mater. Lett 162:5. doi: 10.1016/j.matlet.2015.10.004

Kale, R.B., and Lu, S.-Y. (2015). Air annealing induced transformation of cubic CdSe microspheres into hexagonal nanorods and micro-pyramids. J. Alloys Compd. 640, 504-510. doi: 10.1016/j.jallcom.2015.04.034

Li, C., Wang, F., Chen, Y., Wu, L., Zhang, J., Li, W., et al. (2018). Characterization of sputtered CdSe thin films as the window layer for CdTe solar cells. Mate. Sci. Semi. Proc. 83, 89-95. doi: 10.1016/j.mssp.2018.04.022

Mahato, S., and Kar, A. K. (2017). The effect of annealing on structural, optical and photosensitive properties of electrodeposited cadmium selenide thin films. J. Sci. Adv. Mater. Dev. 2, 165-171. doi: 10.1016/j.jsamd.2017.04.001

Mehta, C., Abbas, J. M., Saini, G., and Tripathi, S. (2007). Effect of deposition parameters on the optical and electrical properties of nanocrystalline CdSe. Chalcog. Lett. 11, 133-138. Available online at: https://chalcogen.ro/charitareviz.pdf

Naushad, M., Khan, M., Bhande, S. S., Shaikh, S. F., Alfadul, S., Shinde, P. V., et al. (2018). High current density cation-exchanged SnO 2-CdSe/ZnSe and
SnO 2-CdSe/SnSe quantum-dot photoelectrochemical cells. N. J. Chem. 42, 9028-9036. doi: 10.1039/C8NJ01409D

Onyia, A. (2017). Optical characteristics of co-deposited zinc antimony sulphide thin films. MDC J. 4, 159-169.

Pal, A., Mondal, A., and Chaudhuri, S. (1990). Preparation and characterization of ZnTe/CdSe solar cells. Vacuum. 41, 1460-1462. doi: 10.1016/0042-207X(90)93990-Z

Pathan, H., Sankapal, B., Desai, J., and Lokhande, C. D. (2003). Preparation and characterization of nanocrystalline CdSe thin films deposited by SILAR method. Mater. Chem. Phys. 78, 11-14. doi: 10.1016/S0254-0584(02)00198-0

Rani, S. S. J. X. (2014). EDAX and FT-IR analysis of annealed electron beam evaporated CdSe thin films. Int. J. Scient. Res. 3, 320-321. doi: 10.15373/22778179/MARCH2014/108

Ravindranadh, K., Ravikumar, R. V. S. S. N., and Rao,. M. C. (2013). Physical and spectral investigation of Co (II) ions doped PVA capped CdSe nanoparticles. J. Non-Oxide Glasses. 5, 39-45.

Rickus, E. (1982). "Photovoltaic behaviour of CdSe thin film solar cells bloss," in Fourth E.C. Photovoltaic Solar Energy Conference, W.H. Grassi G (Dordrecht: Springer), 2. doi: 10.1007/978-94-009-7898-0_139

Rosly, H. N. R., Abdullah, S. F., Harif, M. N., Doroody, C., Chelvanathan, P., Misran, H., et al. (2021). The role of deposition temperature in the photovoltaic properties of RF-sputtered CdSe thin films. Crystals 11:11010073. doi: $10.3390 /$ cryst11010073

Samarth, N., Luo, H., Furdyna, J., Qadri, S., Lee, Y., Ramdas, A., et al. (1989). Growth of cubic (zinc blende) CdSe by molecular beam epitaxy. Appl. Phys. Lett. 54, 2680-2682. doi: 10.1063/1. 101033

Shimizu, K., Yoshida, O., Aihara, S., and Kiuchi, Y. (1971). Characteristics of experimental CdSe vidicons. IEEE Trans. Electron Devices. 18, 1058-1062. doi: 10.1109/T-ED.1971.17331

Shreekanthan, K., Rajendra, B., Kasturi, V., and Shivakumar, G. (2003). Growth and characterization of semiconducting cadmium selenide thin films. Crystal Res. Technol. 38, 30-33. doi: 10.1002/crat.200310003

Smyntyna, V., Gerasutenko, V., Kashulis, S., Mattogno, G., and Reghini, S. (1994). The causes of thickness dependence of CdSe and CdS gas-sensor sensitivity to oxygen. Sens. Actu. B Chem. 19, 464-465. doi: 10.1016/0925-4005(93)01039-7

Sturgis, N.P. (2015). Developing Microfluidic Systems for In Situ Characterization of High Temperature Colloidal Nanoparticle Synthesis. Pennsylvania.

Vishwakarma, S., Kumar, A., Prasad, S., and Tripathi, R. (2013). Synthesis and characterization of $\mathrm{n}$-cdse thin films deposited at different substrate temperature. chalcog. Lett. 10, 393-402.

Xia, X., Liu, Z., Du, G., Li, Y., and Ma, M. (2010). Wurtzite and zincblende CdSe based core/shell semiconductor nanocrystals: Structure, morphology and photoluminescence. J. Lumin. 130, 1285-1291. doi: 10.1016/j.jlumin.2010.02.040

Zhao, L., Hu, L., and Fang, X. (2012). Growth and device application of CdSe nanostructures. Adv. Funct. Mater. 22, 1551-1566. doi: $10.1002 / \mathrm{adfm} .201103088$

Conflict of Interest: The authors declare that the research was conducted in the absence of any commercial or financial relationships that could be construed as a potential conflict of interest.

Copyright (C) 2021 Hussain, Iqbal, Khan, Khan, Mehboob, Ajmal, Ashfaq, Mehboob, Ahmed, Khisro, Li, Chikwenze and Ezugwu. This is an open-access article distributed under the terms of the Creative Commons Attribution License (CC BY). The use, distribution or reproduction in other forums is permitted, provided the original author(s) and the copyright owner(s) are credited and that the original publication in this journal is cited, in accordance with accepted academic practice. No use, distribution or reproduction is permitted which does not comply with these terms. 